\title{
Reversible Obstructive Hydrocephalus from Hypertensive Encephalopathy: A Condition that Neurosurgeons Must Know
}

\section{Hidrocefalia obstrutiva reversível secundária a encefalopatia hipertensiva: uma condição que o neurocirurgião deve conhecer}

\author{
Thiago Pereira Rodrigues ${ }^{1}$ Daniel de Araújo Paz ${ }^{1}$ Marcos Devanir Silva da Costa ${ }^{1}$ Fabio Fieni Toso ${ }^{1}$ \\ Maria Elisabeth Matta de Rezende Ferraz ${ }^{2}$ Fabricio Correa Lamis ${ }^{3}$ Marcos Hideki Idagawa ${ }^{4}$ \\ Luis Antônio Tobaru Tibana ${ }^{5}$ Nitamar Abdala ${ }^{6}$ Sergio Cavalheiro ${ }^{7}$ Italo Capraro Suriano ${ }^{8}$
}

\footnotetext{
${ }^{1}$ Medical Resident, Department of Neurosurgery, Paulista School of Medicine, Universidade Federal de São Paulo (Unifesp), São Paulo, SP, Brazil

2 Neurologist, Head of Emergency Department of Neurology, Paulista School of Medicine, Unifesp, São Paulo, SP, Brazil

${ }^{3}$ Neurosurgeon, Department of Neurology and Neurosurgery,

São Paulo School of Medicine, Unifesp, São Paulo, SP, Brazil

${ }^{4}$ Radiologist, Department of Diagnostic Imaging, São Paulo School of Medicine, Unifesp, São Paulo, SP, Brazil

${ }^{5}$ Radiologist, Head of Neuroradiology Sector, Department of Diagnostic

Imaging, Paulista School of Medicine, Unifesp, São Paulo, SP, Brazil

6 Professor of Radiology, Head of Department of Diagnostic Imaging, Paulista School of Medicine, Unifesp, São Paulo, SP, Brazil

${ }^{7}$ Professor, Department of Neurosurgery, Paulista School of

Medicine, Unifesp, São Paulo, SP, Brazil

${ }^{8}$ Neurosurgeon, Head of Emergency Department of Neurology,

Paulista School of Medicine, Unifesp, São Paulo, SP, Brazil
}

\section{Address for correspondence Thiago Pereira Rodrigues, MR, Rua das Camélias, 29, apto 31, CEP 04048-060, São Paulo, SP, Brazil (e-mail: thiagopereirarodrigues@yahoo.com.br).}

Arq Bras Neurocir 2015;34:64-67.

\section{Abstract \\ Keywords \\ - cerebral edema \\ - hydrocephalus \\ - hypertensive encephalopathy}

Resumo
The vasogenic edema in structures of posterior fossa secondary to elevated hydrostatic pressure can cause obstructive hydrocephalus, a condition called "reversible obstructive hydrocephalus from hypertensive encephalopathy." A case of a 27-year-old woman with arterial hypertension and sign of raised intracranial pressure is reported. Her radiologic studies have showed vasogenic cerebellar edema without structural lesion. This edema leads to obstruction of the cerebral aqueduct. We discuss the clinical and therapeutic aspects of this condition. In this clinical situation, the accurate control of blood pressure is the main goal on medical care, and the need of permanent ventricular shunt is quite infrequent.

O edema vasogênico secundário a elevação da pressão hidrostática capilar pode causar hidrocefalia obstrutiva, a chamada Hidrocefalia Obstrutiva Reversível secundária a Encefalopatia Hipertensiva. Nós apresentamos um caso de uma mulher de 27 anos com received

April 2, 2014

accepted

November 1, 2014
DOI http://dx.doi.org/ $10.1055 / \mathrm{s}-0035-1547388$ ISSN $0103-5355$.
Copyright $\odot 2015$ by Thieme Publicações License terms

Ltda, Rio de Janeiro, Brazil c) $(1) \$$ 
Palavras-chave

- edema encefálico

- hidrocefalia

- encefalopatia hipertensiva hipertensão arterial e sinais de hipertensão intracraniana. Sua investigação radiológica evidenciou sinais de edema vasogênico cerebelar bilateral sem lesão estrutural, determinando obstrução do aqueduto cerebral Nós discutimos os aspectos clínicos e terapêuticos deste caso. Nesta condição, o adequado controle da pressão arterial é a principal medida terapêutica, sendo a necessidade de derivação liquórica permanente infrequente.

\section{Introduction}

The vasogenic edema in posterior fossa structures, which comprehends brainstem and cerebellum, can block cerebrospinal fluid circulation at this level causing obstructive hydrocephalus. ${ }^{1}$ There are many causes that can create vasogenic edema in this region, highlighting increase in endothelial permeability secondary to inflammatory or tumorous humors. Another possible cause is elevated hydrostatic pressure in capillary bed. ${ }^{2}$ This article describes a woman with clinical and radiologic findings of reversible obstructive hydrocephalus from hypertensive encephalopathy.

\section{Clinical Presentation}

A 27-year-old woman presented with a 7-day history of progressive holocranial headache associated with 2 days of vomits followed by 1-day history of progressive lethargy. Her medical history showed related end-stage kidney failure secondary to polycystic kidney disease that was submitted to a kidney transplant 16 years ago. This transplant failed 2 years ago and since then three times a week hemodialysis program was followed.

Her physical findings included 180/100-mm Hg blood pressure, 13 points on Glasgow coma scale, and papilledema founded by direct funduscopy.

Intravenous sodium nitroprusside was used at rate of $0.25 \mu \mathrm{g} / \mathrm{kg} / \mathrm{min}$ and complemented by laboratories and radiologic investigation. No evidential findings of electrolyte imbalances were found, and computed tomography (CT) of the head revealed lateral and third ventricular dilatation associated with swelled elements of posterior fossa (- Fig. 1).

During the follow-up, a gradual pressure control was achieved, and the patient showed important improvement on her clinical condition. In 24 hours from admission, 15 points on Glasgow coma scale were stablished, without any neurologic impairment.

Magnetic resonance imaging (MRI) done 5 days later (-Fig. 2) showed a hypointense signal on T1-weighted sequence, hyperintense on T2-weighted and flair on subcortical area of both cerebellar hemispheres, characteristic of vasogenic edema. A careful inspection of diffusion sequence did not show any restriction area, which did not support the diagnosis of cerebellar infarction ${ }^{3}$ (-Fig. 3). A new study of MRI (-Fig. 4) done 12 days ahead of admission showed important reduction in cerebellar findings and complete resolution of obstructive hydrocephalous.

The patient was discharged in 13 days without any neurologic impairment.

\section{Discussion}

We know that the rise in blood pressure above cerebral autoregulation limits of cerebral blood flow can cause higher capillary hydrostatic pressure levels that lead to vasogenic edema. In these circumstances, when blood pressure transposes the autoregulation limit, the patient can evolve with the clinical condition called hypertensive encephalopathy.

In 1996, Hinchey et $\mathrm{al}^{4}$ identified a clinical and radiologic condition that they called posterior reversible encephalopathy syndrome (PRES). Their clinical findings were mainly

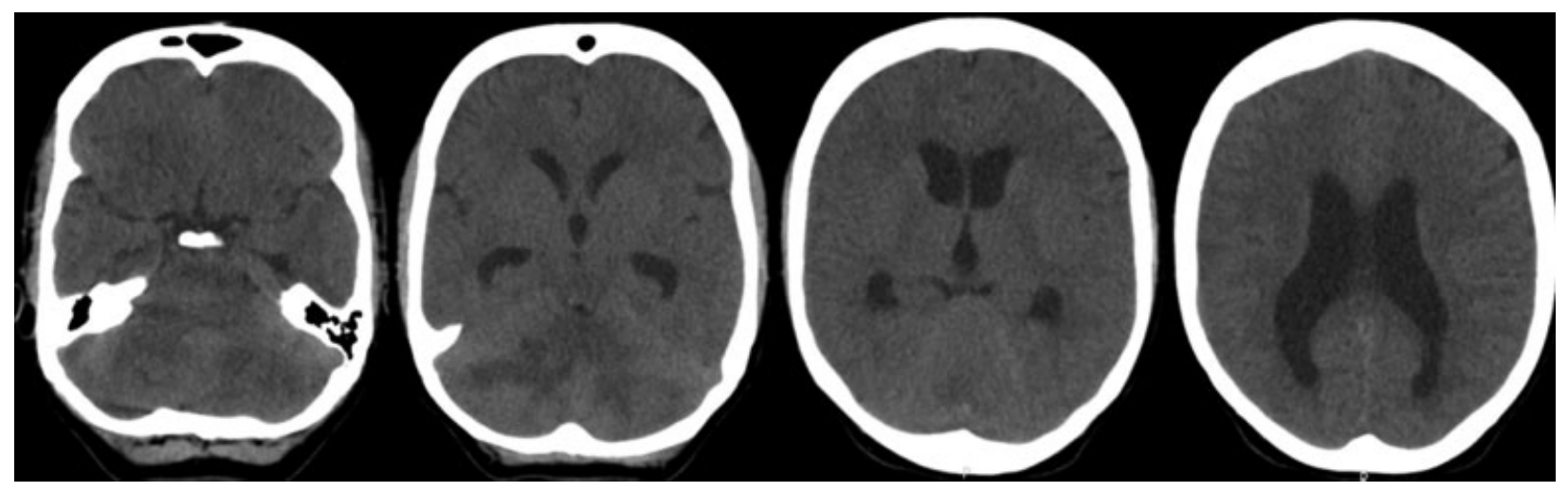

Fig. 1 Initial CT scan demonstrates a symmetric cerebellar hypodensity with mass effect and obstructive hydrocephalus. 


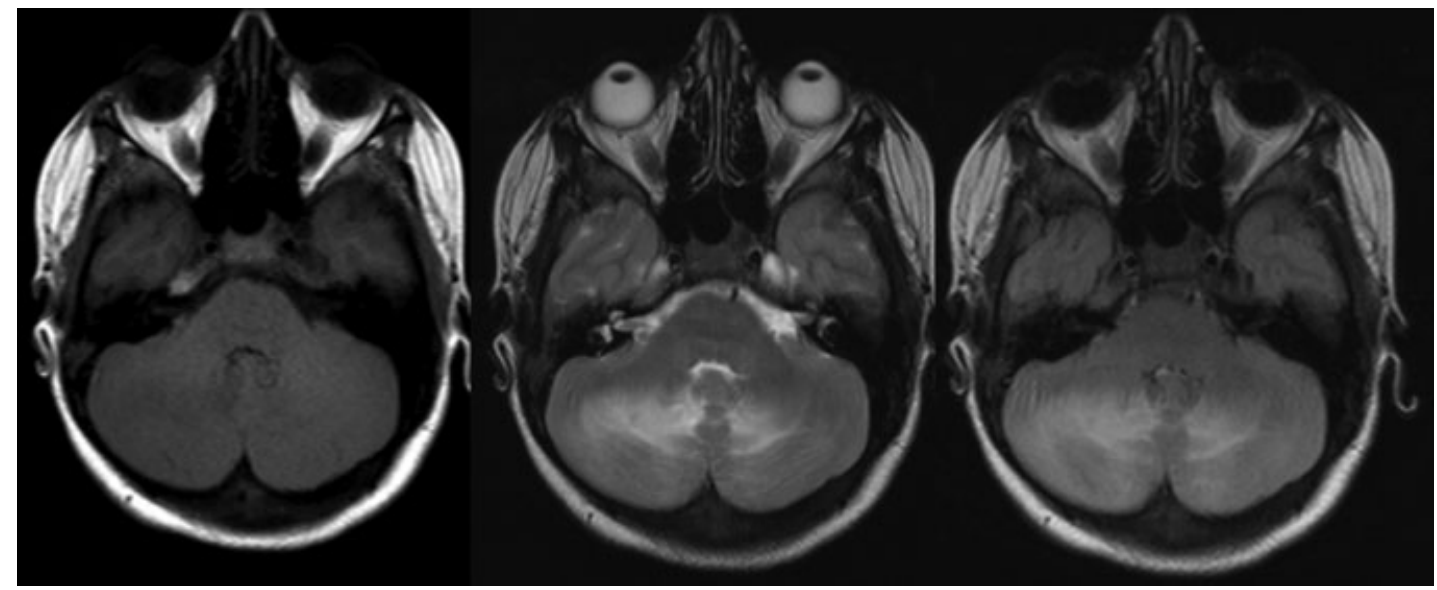

Fig. 2 Initial MRI scan reveals hypointensity signal on T1-weighted sequence, hyperintense on T2-weighted and flair on subcortical area of both cerebellar hemispheres.

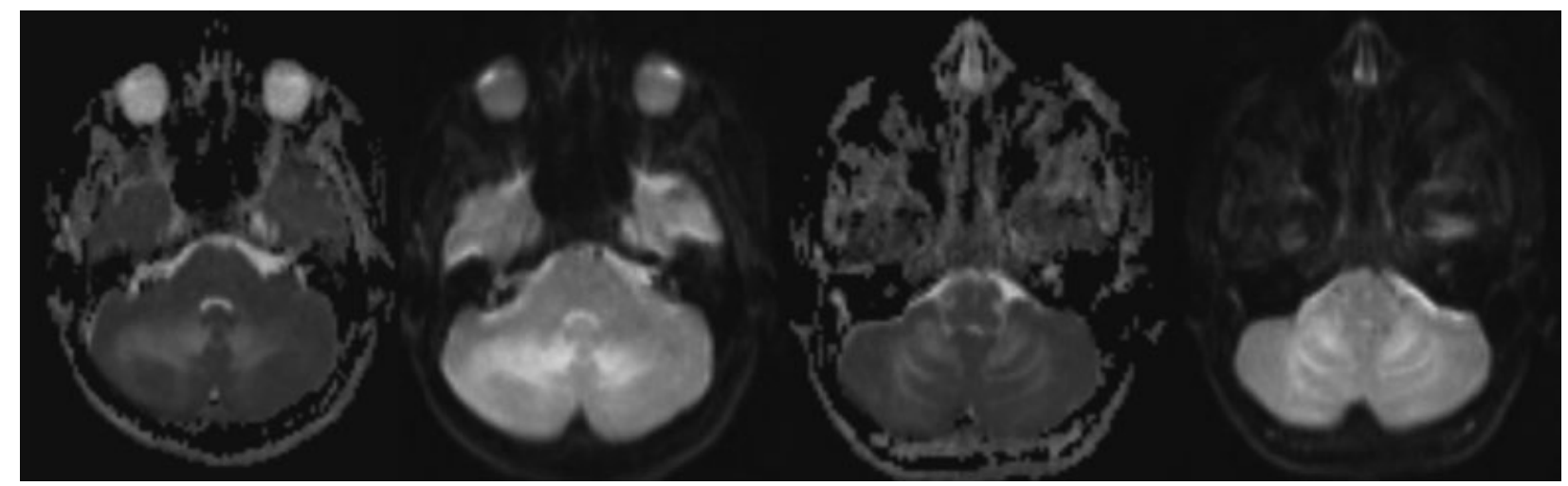

Fig. 3 The diffusion-weighted (DW) images and corresponding apparent diffusion coefficient (ADC) map show no sign of cerebellar infarction.

characterized by seizures, headache, impaired level of conscience, vomiting, and sight abnormalities, being seizure the most frequent among these. The radiologic acquisitions reveal preferential white matter lesion, especially on territories supplied by vertebrobasilar circulation, ${ }^{4}$ which happens usually in a bilateral pattern. ${ }^{3}$ This fact can be explained by the diminished sympathetic innervation when compared with carotid system, which predispose to break in cerebral blood flow autoregulation. ${ }^{5}$

Particularly, the parietooccipital transition is reached in the biggest majority of cases, in association to another region or as isolated pattern. The lonely lesion of other regions, without parietooccipital impairment, is rare. The isolated brainstem and cerebellum are much more infrequent. ${ }^{5,6}$

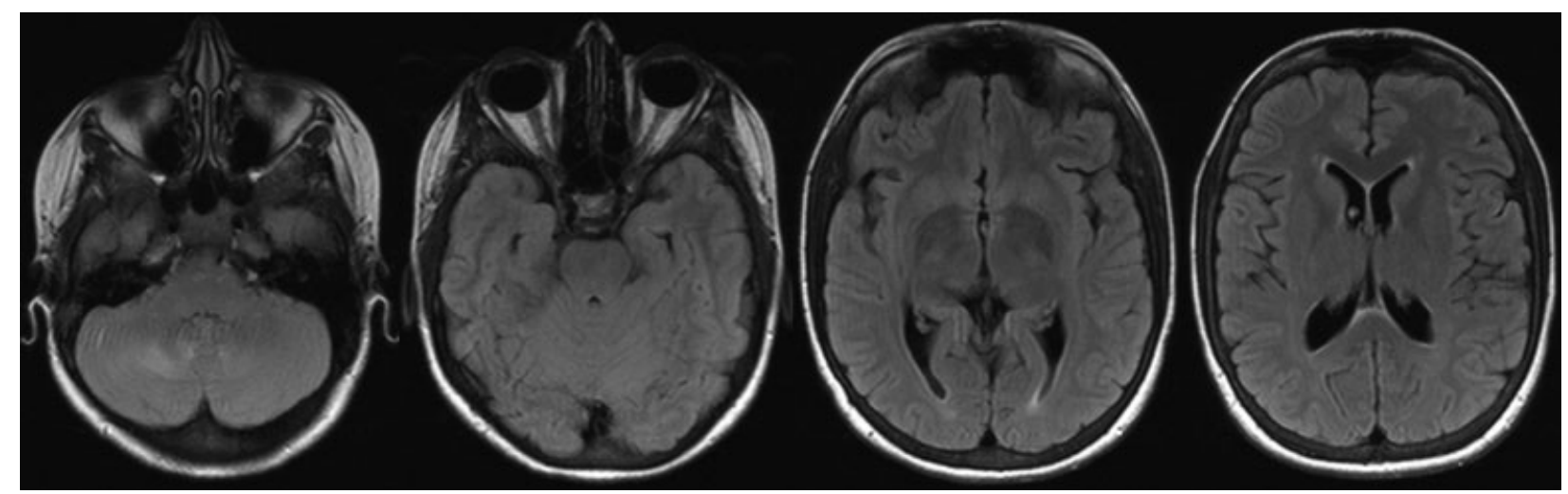

Fig. 4 A MRI done 12 days ahead of admission demonstrates important reduction in cerebellar mass effect and hydrocephalus. 
In 2012, Kumar et $\mathrm{al}^{1}$ described a three-case series that was similar to the case reported in this article and after conducting a research that found other 15 cases. At that occasion, they named it as reversible obstructive hydrocephalus from hypertensive encephalopathy, emphasizing that the accurate blood pressure control must be the primary target on clinical care of these patients. In this study, just 1 of the 18 patients needed permanent ventricular shunt.

In conclusion, the hypertensive encephalopathy can be a cause of obstructive hydrocephalous. The accurate control of blood pressure is the main goal of medical care, and the need of permanent ventricular shunt is quite infrequent.

Conflicts of Interest

The authors declare no conflict of interest.

\section{References}

1 Kumar A, Keyrouz SG, Willie JT, Dhar R. Reversible obstructive hydrocephalus from hypertensive encephalopathy. Neurocrit Care 2012;16(3):433-439

2 Larsen FS, Wendon J. Brain edema in liver failure: basic physiologic principles and management. Liver Transpl 2002;8(11): 983-989

3 Kidwell CS, Alger JR, Di Salle F, et al. Diffusion MRI in patients with transient ischemic attacks. Stroke 1999;30(6):1174-1180

4 Hinchey J, Chaves C, Appignani B, et al. A reversible posterior leukoencephalopathy syndrome. N Engl J Med 1996;334(8): 494-500

5 Edvinsson L, Owman C, Siesjö B. Physiological role of cerebrovascular sympathetic nerves in the autoregulation of cerebral blood flow. Brain Res 1976;117(3):519-523

6 Bhagavati S, Chum F, Choi J. Hypertensive encephalopathy presenting with isolated brain stem and cerebellar edema. J Neuroimaging 2008;18(4):454-456 